\title{
Syrinx location and size according to etiology: identification of Chiari-associated syrinx
}

\author{
Jennifer Strahle, MD, Karin M. Muraszko, MD, Hugh J. L. Garton, MD, MHSc, \\ Brandon W. Smith, MD, MS, Jordan Starr, BS, Joseph R. Kapurch II, MD, \\ and Cormac O. Maher, MD
}

Department of Neurosurgery, University of Michigan, Ann Arbor, Michigan

\begin{abstract}
OBJECT Syrinx size and location within the spinal cord may differ based on etiology or associated conditions of the brain and spine. These differences have not been clearly defined.

METHODS All patients with a syrinx were identified from 14,118 patients undergoing brain or cervical spine imaging at a single institution over an 11-year interval. Syrinx width, length, and location in the spinal cord were recorded. Patients were grouped according to associated brain and spine conditions including Chiari malformation Type I (CM-I), secondary $\mathrm{CM}\left(2^{\circ} \mathrm{CM}\right)$, Chiari malformation Type $0(\mathrm{CM}-0)$, tethered cord, other closed dysraphism, and spinal tumors. Syringes not associated with any known brain or spinal cord condition were considered idiopathic. Syrinx characteristics were compared between groups.
\end{abstract}

RESULTS A total of 271 patients with a syrinx were identified. The most common associated condition was CM-I (occurring in 117 patients [43.2\%]), followed by spinal dysraphism (20 [7.4\%]), tumor (15 [5.5\%]), and tethered cord (13 [4.8\%]). Eighty-three patients $(30.6 \%)$ did not have any associated condition of the brain or spinal cord and their syringes were considered idiopathic. Syringes in patients with CM-I were wide $(7.8 \pm 3.9 \mathrm{~mm})$ compared with idiopathic syringes $(3.9 \pm$ $1.0, p<0.0001)$ and those associated with tethered cord $(4.2 \pm 0.9, p<0.01)$. When considering CM-I-associated and idiopathic syringes, the authors found that $\mathrm{CM}$-I-associated syringes were more likely to have their cranial extent in the cervical spine (88\%), compared with idiopathic syringes $(43 \%$; $p<0.0001)$. The combination of syrinx width greater than $5 \mathrm{~mm}$ and cranial extent in the cervical spine had $99 \%$ specificity $(95 \% \mathrm{Cl} 0.92-0.99)$ for CM-I-associated syrinx.

CONCLUSIONS Syrinx morphology differs according to syrinx etiology. The combination of width greater than $5 \mathrm{~mm}$ and cranial extent in the cervical spine is highly specific for CM-I-associated syringes. This may have relevance when determining the clinical significance of syringes in patients with low cerebellar tonsil position.

http://thejns.org/doi/abs/10.3171/2014.12.PEDS14463

KEY WORDS Chiari malformation; scoliosis; syrinx; congenital

$\mathrm{S}$ YRINGOMYELIA is a common reason for neurosurgical referral. Syringes may be associated with a number of different brain or spinal cord conditions including Chiari malformation Type I (CM-I), CM secondary to other intracranial pathology such as craniosynostosis (secondary $\left.\mathrm{CM}, 2^{\circ} \mathrm{CM}\right)$, Chiari malformation Type 0 (CM-0), tethered cord, other closed dysraphism, trauma, and spinal tumors. ${ }^{16,24,26,28,30}$ Some syringes are not associated with any of these conditions and may be considered idiopathic. $3,14,18,19,23$

It is well established that large cervical cord syringes in patients with typical-appearing CM-I are causally linked in many cases. Decompression of the CM-I leads to a reduction in syrinx size in a significant majority of cases. ${ }^{30}$ In our view, the causative relationship for CM-I and syrinx is less certain for small syringes or syringes located more caudally in the spinal cord. The assignment of causation of a spinal syrinx to concurrent low position of the cerebellar tonsils, however, is clinically relevant. Surveys of pediatric neurosurgeons consistently show that surgeons are more willing to recommend CM-I decompression when a syrinx is present, even in the absence of other symptoms of CMI. ${ }^{22,25}$ In one survey, $28 \%$ of pediatric neurosurgeon respondents recommended CM-I decompression in an oth-

ABBREVIATIONS $\mathrm{CM}=$ Chiari malformation; $\mathrm{CM}-\mathrm{I}=\mathrm{CM}$ Type I; $\mathrm{CM}-0=\mathrm{CM}$ Type $0 ; 2^{\circ} \mathrm{CM}=$ secondary $\mathrm{CM}$.

SUBMITTED August 29, 2014. ACCEPTED December 15, 2014.

INCLUDE WHEN CITING Published online April 3, 2015; DOI: 10.3171/2014.12.PEDS14463.

DISCLOSURE The authors have no conflicts of interest to report pertaining to the materials or methods used in this study or the findings specified in this paper. 
erwise asymptomatic patient with CM-I and a 2-mm-wide "syrinx," a substantially higher percentage than those who would recommend surgery for the same patient without this finding on spine MRI. ${ }^{25}$ If the syrinx in this hypothetical asymptomatic patient was $8 \mathrm{~mm}$ wide, then $75 \%$ of respondents recommended surgery. ${ }^{25} \mathrm{~A}$ more recent survey confirmed that most pediatric neurosurgeons continue to recommend surgery for otherwise asymptomatic patients with CM-I and syrinx. ${ }^{22}$ Because both CM-I and syringomyelia are not uncommon incidental findings on imaging, and decompression is frequently recommended for CM-I patients with syrinx found on MRI, it is important to address whether all such syringes are likely related to the CM-I, or whether in some cases other forces are at work that may not necessarily respond to posterior fossa decompression. Our goal was to analyze syrinx size and location of syringes associated with CM-I and other brain and spine conditions as well as idiopathic syringes to better define differences between syrinx types. We hope that this information will allow clinicians to more accurately predict the likelihood of a causative or coincidental relationship when evaluating a patient with CM-I and a syrinx.

\section{Methods}

Following University of Michigan Institutional Review Board approval, all patients with a syrinx were identified from a group of 14,118 consecutive patients who underwent brain or cervical spine MRI over an 11-year interval at the University of Michigan. The most frequent indication for imaging was scoliosis, followed by pain and weakness. Electronic records were reviewed using the Electronic Medical Record Search Engine (EMERSE) ${ }^{9}$ to identify patients with syrinx using the key words "syrinx", "syringomyelia", and "hydromyelia". Syrinx was defined as an intramedullary spinal cord cyst that was hypointense on T1-weighted imaging and hyperintense on T2weighted imaging, without contrast enhancement. Syrinx size and location were recorded. To be included in this analysis, the syrinx must have measured at least $3 \mathrm{~mm}$ in its maximum dimension on axial imaging. Intramedullary cavitations measuring less than $3 \mathrm{~mm}$ were excluded from analysis. Syrinx characteristics were recorded, including cranial and caudal extent and syrinx width. Syrinx level was evaluated according to the adjacent vertebral body or disc space, and the cranial and caudal extent of the syrinx were recorded according to the number of levels from the foramen magnum.

Patients were divided into 9 groups according to any associated brain or spinal cord condition (Table 1, Fig. 1). Those patients with cerebellar tonsil position $5 \mathrm{~mm}$ or more below the foramen magnum were assigned to the $\mathrm{CM}$ group. If low tonsil position was thought to be secondary to another associated intracranial condition, such as brain tumor or craniosynostosis, patients were assigned to the $2^{\circ} \mathrm{CM}$ group. All cases of $2^{\circ} \mathrm{CM}$ in this cohort were secondary to craniosynostosis. In rare cases, patients were considered to have $\mathrm{CM}-0$ by the treating physician. These patients were also considered separately. We considered the diagnosis of CM-0 in patients with a syrinx who had evidence of cerebellar tonsil impaction and distortion at the foramen magnum with evidence of CSF flow impairment but did not meet the usual imaging criteria for CM-I in that the cerebellar tonsil position was less than $5 \mathrm{~mm}$ below the foramen magnum as defined by the basion-opisthion line. ${ }^{4}$

Associated spinal conditions included closed spinal dysraphism and simple tethered cord. These were considered as two separate groups-the closed "spinal dysraphism" group included patients with lipomyelomeningocele, diastematomyelia, intradural lipoma not confined to the filum terminale, myelocystocele, and meningocele, while the "tethered cord" group included only those patients with low conus position below the L-2 vertebral body and fatty filum terminale without other features of closed dysraphism. For this analysis, patients were considered to have simple tethered cord if they were not included in the other closed dysraphism group and if the treating physician made a diagnosis of tethered cord. This diagnosis was made on the basis of patient symptoms as well as the presence of a low-lying conus or a fatty filum. A conus position below the inferior margin of the L-2 body is generally considered low-lying at our institution. ${ }^{6} \mathrm{~Pa}$ tients with syringes that were secondary to spinal tumor, spinal trauma, and other conditions such as infection and spinal arachnoid cyst were also considered separately. Patients were excluded if there was a history of CM Type II or open spinal dysraphism. Patients who received surgical treatment for CM-I prior to their first MRI at our institution were also excluded. Scoliosis was defined as a lateral Cobb angle of at least $10^{\circ}$ on radiography.

Statistical significance calculations were obtained using 2-tailed t-test for continuous variables and Fisher exact test for categorical variables, and $p$ values $<0.05$ were considered significant. Sensitivity and specificity calculations were performed with $95 \%$ confidence intervals. Data were analyzed using StatPlus software (AnalystSoft Inc.).

\section{Results}

A total 271 patients (1.9\%) with a syrinx at least $3 \mathrm{~mm}$ in maximum axial dimension were identified. CM-I was the most frequent associated condition (present in $117 \mathrm{pa}-$ tients [43.2\%]), followed by spinal dysraphism (20 [7.4\%]), tumor (15 [5.5\%]), tethered cord (13 [4.8\%]), and $2^{\circ} \mathrm{CM}(13$ [4.8\%]) (Table 1, Fig. 1). No associated brain or spinal cord condition was found in 83 patients (30.6\%), and syringes in these patients were considered idiopathic.

Syrinx characteristics differed according to associated condition. In general, syringes associated with CM-I, $2^{\circ} \mathrm{CM}$, tumor, and dysraphism were wide compared with idiopathic syringes (Fig. 2). Syringes in patients with CM-I had a mean maximum width of $7.8 \pm 3.9 \mathrm{~mm}$, similar to those in patients with CM-0 $(8.3 \pm 3.7 \mathrm{~mm})$ or $2^{\circ} \mathrm{CM}(7.9$ $\pm 3.6 \mathrm{~mm}$ ). In contrast to CM-I-associated syringes, idiopathic syringes had a mean maximum axial dimension of only $3.9 \pm 1.0 \mathrm{~mm}(\mathrm{p}<0.0001)$. Syringes associated with tethered cord were also narrower than CM-I-associated syringes $(4.2 \pm 0.9 \mathrm{~mm}, \mathrm{p}<0.01)$. Syringes associated with spinal dysraphism were wider $(5.7 \pm 3.0 \mathrm{~mm})$ than idiopathic syringes and syringes associated with simple tethered cord, but narrower than CM-I-associated syringes. 


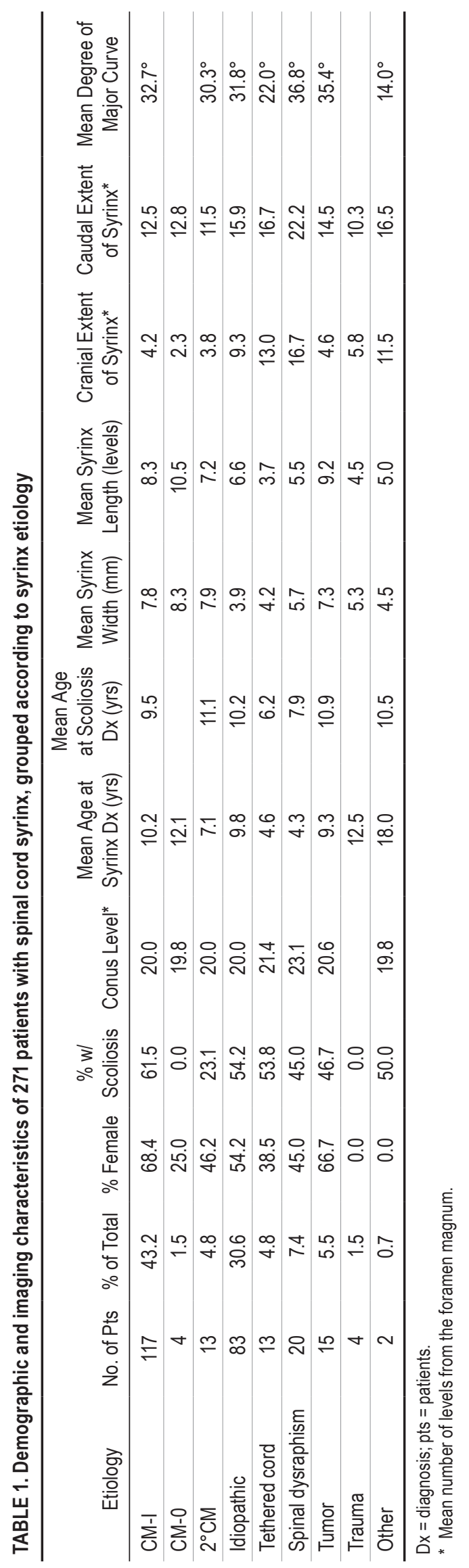

Almost all idiopathic syringes were less than or equal to 5 $\mathrm{mm}$ in maximum axial dimension (79 syringes [95.2\%]). In patients with CM-I, only $31.6 \%$ of syringes (37 syringes) were $5 \mathrm{~mm}$ or less in maximum axial dimension (Figs. 2 and 3 ).

Syrinx location within the spinal canal also differed according to associated condition (Fig. 4). Syringes associated with CM-I, CM- 0 , or $2^{\circ} \mathrm{CM}$ had a more superior cranial extent, usually in the cervical spine. Syringes associated with tethered cord and spinal dysraphism were more likely to have their cranial and caudal extents located more caudally. Idiopathic syringes had an intermediate position within the spinal canal. CM-I-associated syringes were longer than idiopathic syringes $(8.3 \pm 5.9$ vs $6.6 \pm 4.8$ levels, respectively; $p<0.05$ ) (Fig. 5). In 12 patients, the syringes were limited to the T-12 segment or below. Nine of these 12 patients had a tethered cord, and 3 had a normal conus position.

Scoliosis, defined as a Cobb angle of at least $10^{\circ}$, was found in 144 patients (53.1\%). The incidence of scoliosis did not differ significantly by associated condition, with the exception that patients with $2^{\circ} \mathrm{CM}$ were less likely to have scoliosis (Fig. 6). The mean age at scoliosis diagnosis was $9.6 \pm 4.5$ years. Those with spinal dysraphism $(7.9 \pm$ 5.2 years) and tethered cord (6.2 \pm 5.5 years) were diagnosed with scoliosis at a younger age (Table 1). For idiopathic syrinx, there was a similar number of patients with and without scoliosis for a given syrinx width. For patients with CM-I-associated syrinx with narrower widths (< $9 \mathrm{~mm}$ ), there were similar numbers of patients with and without scoliosis for a given syrinx width. However, most CM-I patients with wide syringes $(>9 \mathrm{~mm})$ had scoliosis (Fig. 7).

We evaluated conus level to rule out occult spinal cord tethering in patients with idiopathic syrinx, as their width morphology was similar to those with tethered cord. We found a normal mean conus position in patients with idiopathic syrinx, in contrast to those with tethered cord and those with spinal dysraphism (Fig. 8), in whom a low conus position was expected. The mean conus position for patients with CM-I and syrinx was in the normal range.

When looking at the cranial extent of syringes, we found that it was in the cervical spine in $88 \%$ of patients with CM-I-associated syringes compared with $43 \%$ of patients with idiopathic syringes ( $\mathrm{p}<0.0001)$. A small number of patients with CM-I had narrow syringes with cranial extent in the thoracic or lumbar spine, more similar in morphology to that of an idiopathic syrinx than a typical CM-I-associated syrinx. Despite these outliers, however, the combination of syrinx width greater than $5 \mathrm{~mm}$ and cranial extent in the cervical spine had $99 \%$ specificity (95\% CI $0.92-0.99$ ) and 64\% sensitivity (95\% CI $0.55-$ 0.73 ) for CM-I-associated syrinx. Conversely, syrinx width of $5 \mathrm{~mm}$ or less and cranial extent in the thoracic or lumbar spine had $92 \%$ specificity (95\% CI 0.86-0.96) and $54 \%$ sensitivity (95\% CI $0.42-0.65$ ) for idiopathic syrinx.

The mean age at the time of syrinx diagnosis, including patients in all groups, was $9.3 \pm 5.3$ years. Syringes associated with tethered cord and spinal dysraphism were diagnosed earlier, with a mean age at the time of diagnosis of $4.6 \pm 4.7$ years for tethered cord-associated syrinx, and 


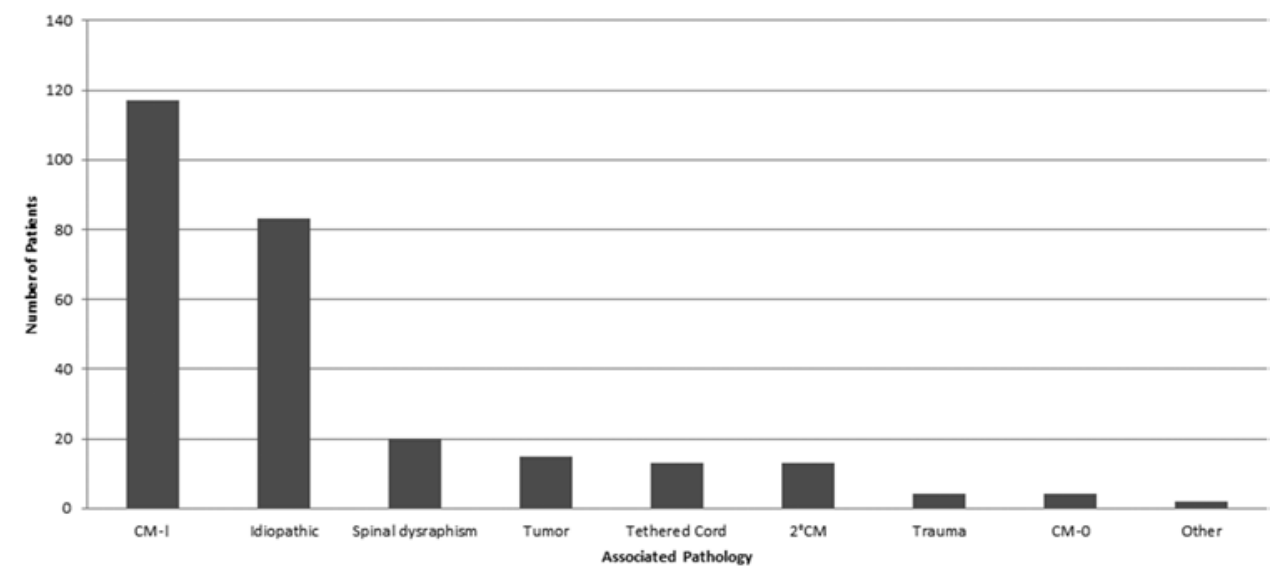

FIG. 1. Number of patients with syrinx according to associated pathology.

$4.3 \pm 4.7$ years for syringes associated with spinal dysraphism. The mean age at diagnosis of syringes associated with CM-I was $10.2 \pm 4.8$ years, and for idiopathic syringes the mean age at diagnosis was $9.8 \pm 5.2$ years. Syringes associated with $2^{\circ} \mathrm{CM}$ were also diagnosed at a young age ( $7.1 \pm 4.4$ years).

\section{Discussion}

Spinal syringes may result from several possible etiologies or, in idiopathic cases, may have no discernable etiology at all..$^{10,11}$ It is well established that CM-I may lead to syrinx formation. ${ }^{2,5,8,10,20,28,30}$ Most contemporary reports have suggested that abnormal flow of CSF at the craniocervical junction leads to syrinx formation. ${ }^{4,5,10,17,20,27,28,31}$ However, given the relatively common incidence of CM-I and syrinx found in patients undergoing MRI, it is also possible that in some cases, a patient with low tonsil position also will have an intramedullary spine cyst for reasons unrelated to the CM-I. This idea is reinforced by clinical experience, in that syringes are quite variable in terms of size and position within the spinal canal. When a patient with a syrinx also has a CM-I, can we determine how likely it is that the CM-I has actually caused the syrinx? This determination is clinically important, since the presence of a syrinx may be used as a justification for CM-I decompression in some cases. ${ }^{1,22,25,26}$

Since syringes may be caused by multiple associated conditions or even, for idiopathic syringes, have no known cause at all, it follows that not all syringes found in patients with CM-I are necessarily caused by the CM-I. There are several facts that establish the relationship between CM-I and syringomyelia. First, syringes occur with significantly increased frequency in those with CM-I and reliably improves following CM-I decompression. . $^{13,28,30}$ Many groups have plausibly described how changes in CSF flow at the foramen magnum can lead to syrinx formation. ${ }^{10,20}$ We have

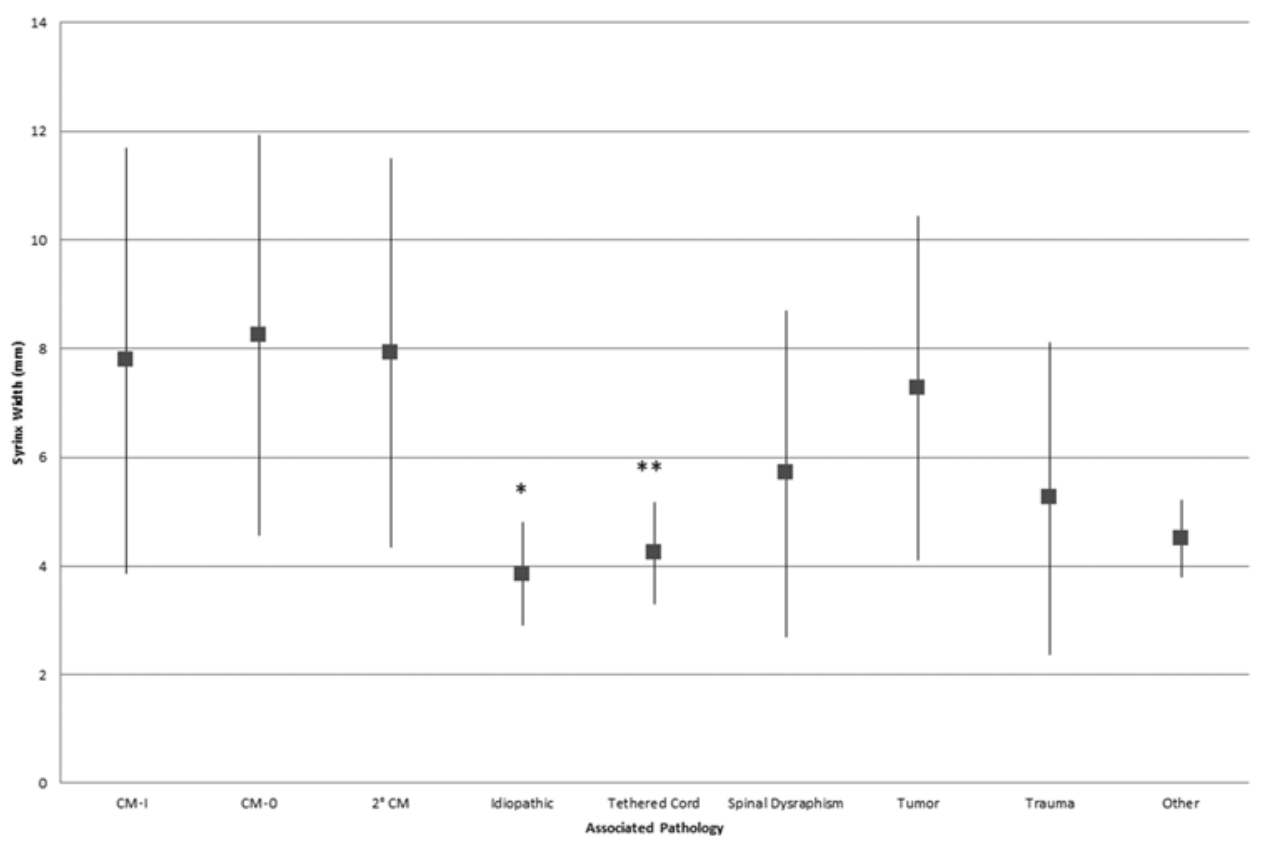

FIG. 2. Syrinx width according to associated pathology. Mean maximum width values and SDs are shown. ${ }^{*} p<0.0001,{ }^{* *} p<0.01$. 


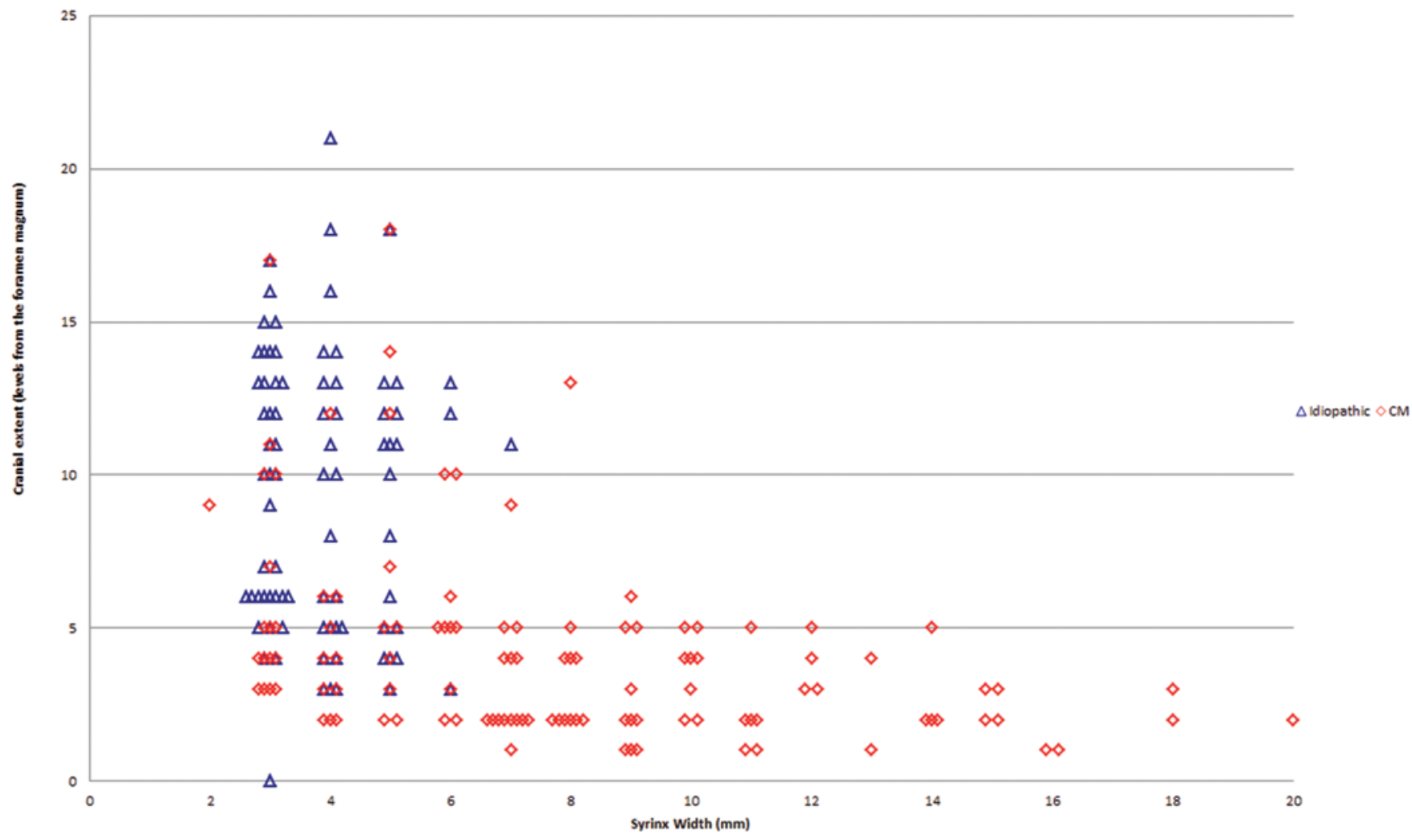

FIG. 3. Patients with idiopathic and CM-I-associated syrinx grouped according to maximum syrinx width and cranial extent of syrinx. Figure is available in color online only.

shown that CM-I-associated syringes are also usually distinct in location and size. We found that CM-I-associated syringes had a larger mean axial dimension compared with other types and were more likely to have a cranial extent in the cervical spine. These findings are consistent with prior reports of CM-I-associated syringes. ${ }^{10,28}$ Taken together, these facts imply that the mechanism of syrinx formation in CM-I-associated cases is likely to be different than in syringes of a different morphological appearance. Mean syrinx length, however, was not useful in differentiating CM-I-associated syringes from idiopathic syringes.

Thin, idiopathic syringes have a benign natural history and almost certainly have a pathophysiology distinct from that of CM-I-associated syringes. ${ }^{12,23,26}$ In general, idiopathic syringes have a different morphology and location, tending to be narrower than $\mathrm{CM}$-associated syringes and not as frequently located in the cervical spine.,12,14,18,23 They are usually asymptomatic, incidental findings, and in most cases require no treatment. ${ }^{12,14,18,23,26}$ All patients in this series had a syrinx width of at least $3 \mathrm{~mm}$. There is no consensus definition for distinguishing a narrow syrinx from the very common finding of a dilated central canal on imaging. Some groups have used a minimum width threshold of $2 \mathrm{~mm}$ for an imaging diagnosis of syrinx; we used $3 \mathrm{~mm}$ width as the inclusion criterion for syrinx in this analysis. ${ }^{18,21}$ We prefer the 3 -mm definition, since it is more likely to exclude very thin central spinal fluid collections that blend into the category of dilated central canal. The threshold of $3 \mathrm{~mm}$ allows for a greater focus on MRI findings that most would consider diagnostic of a syrinx.
Conus level was evaluated, as it has previously been suggested by others that some patients with CM-I have a low-lying conus. ${ }^{30-32}$ We did not find any difference in conus position in patients with CM-I-associated syrinx compared with patients with idiopathic syrinx. The fact that tethered cord syringes are narrow and usually located caudally in the spine suggests a distinct pathophysiology

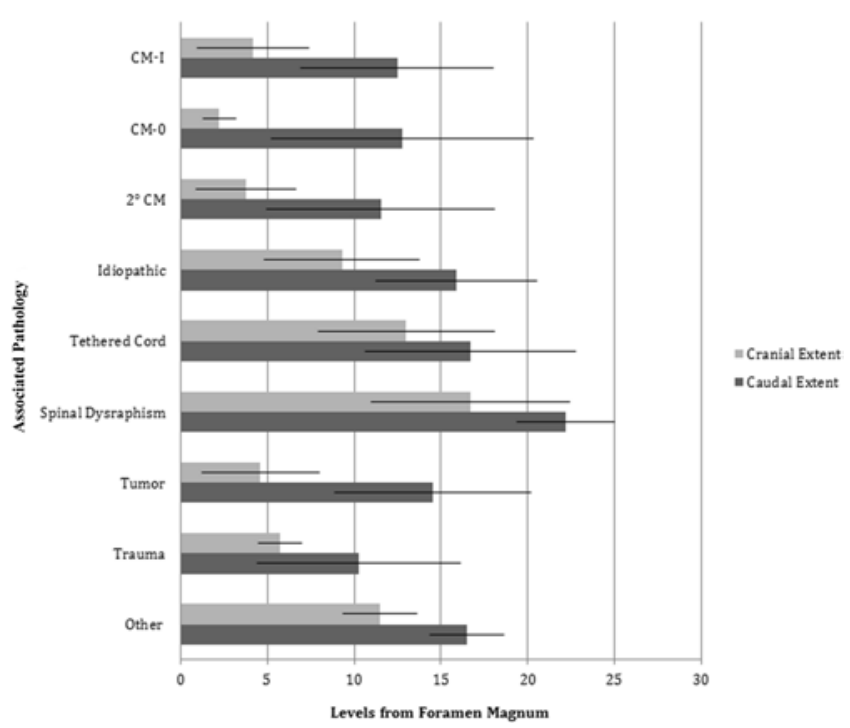

FIG. 4. Cranial and caudal extent of syrinx (mean number of levels). Error bars indicate SDs. 


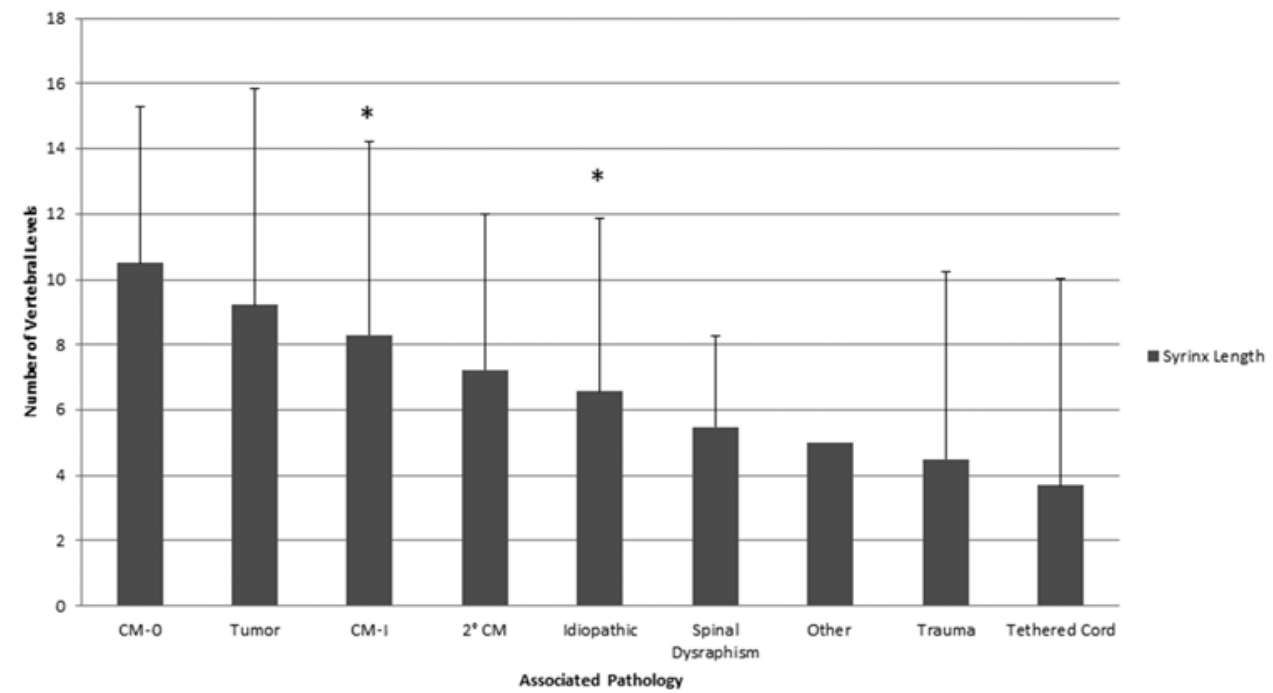

FIG. 5. Syrinx length (mean number of levels) according to syrinx etiology. Error bars indicate SDs. ${ }^{*} p<0.05$.

for this group as well. Nine of the 12 patients with a syrinx confined to the lowest segments (T-12 or below) had a low conus position. Three patients with a syrinx at or below the T-12 level had no evidence of tethered cord, and their cases may be consistent with a diagnosis of a benign distal syrinx, although for the purposes of this analysis, we made no attempt to separate these patients from the idiopathic syrinx group. Our finding that these syringes tend to be located caudally in the spinal cord is consistent with the small series previously reported by Kulwin et al ${ }^{16}$ In our cohort, patients with tethered cord were diagnosed earlier. Ten of the 22 patients in our series with a cutaneous mark on the back had a tethered cord. It is possible that this association with cutaneous stigmata led to an earlier mean age of diagnosis in the group with tethered cord.

Although we may conclude that most syringes in patients with CM-I are caused by the CM-I, it is likely that a small number of syringes in these patients may be idiopathic or caused by another agent. For the purposes of this analysis, we treated all syringes in patients with CM-I as
"CM-I-associated syringes." Nevertheless, there are clearly syringes within this group that do not share the typical features of the group, either because they are narrow or because they are inferiorly located or for both reasons. It is possible that these outliers represent patients who could be considered to have another syrinx type and coincidentally low cerebellar tonsil position. Our data support a strong link between wide, rostrally located syringes and CM-I, but no such strong link for thin, inferiorly located syringes. On the basis of these results, when an otherwise asymptomatic patient with CM-I presents with a syrinx that is not typical for a CM-I-associated syrinx, we would not offer CM-I decompression in our practice. We would be more likely to consider prophylactic CM-I decompression for a patient with a typical wide, cervical CM-I-associated syrinx.

While the pathophysiology for CM-I-associated syrinx has received much attention, ${ }^{20}$ less attention has been given to idiopathic syringomyelia. As idiopathic syringes are clearly different both in their behavior ${ }^{18}$ and morphology, it

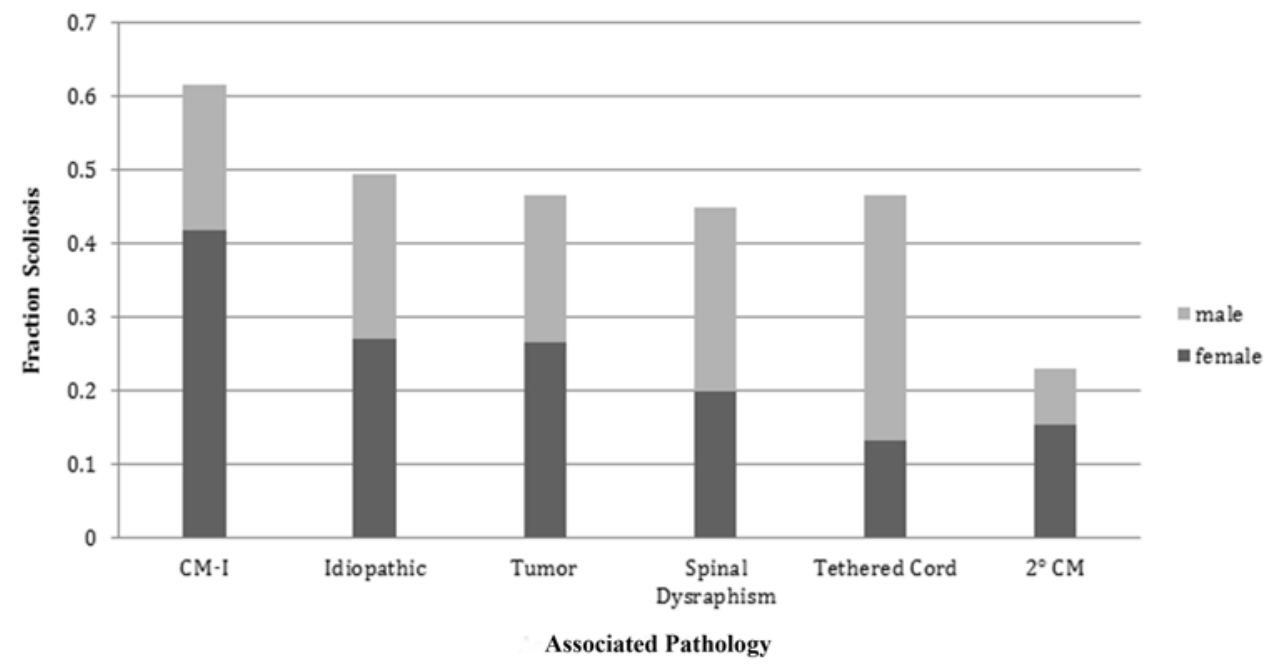

FIG. 6. Fraction of patients with scoliosis according to syrinx etiology, stratified by sex. 

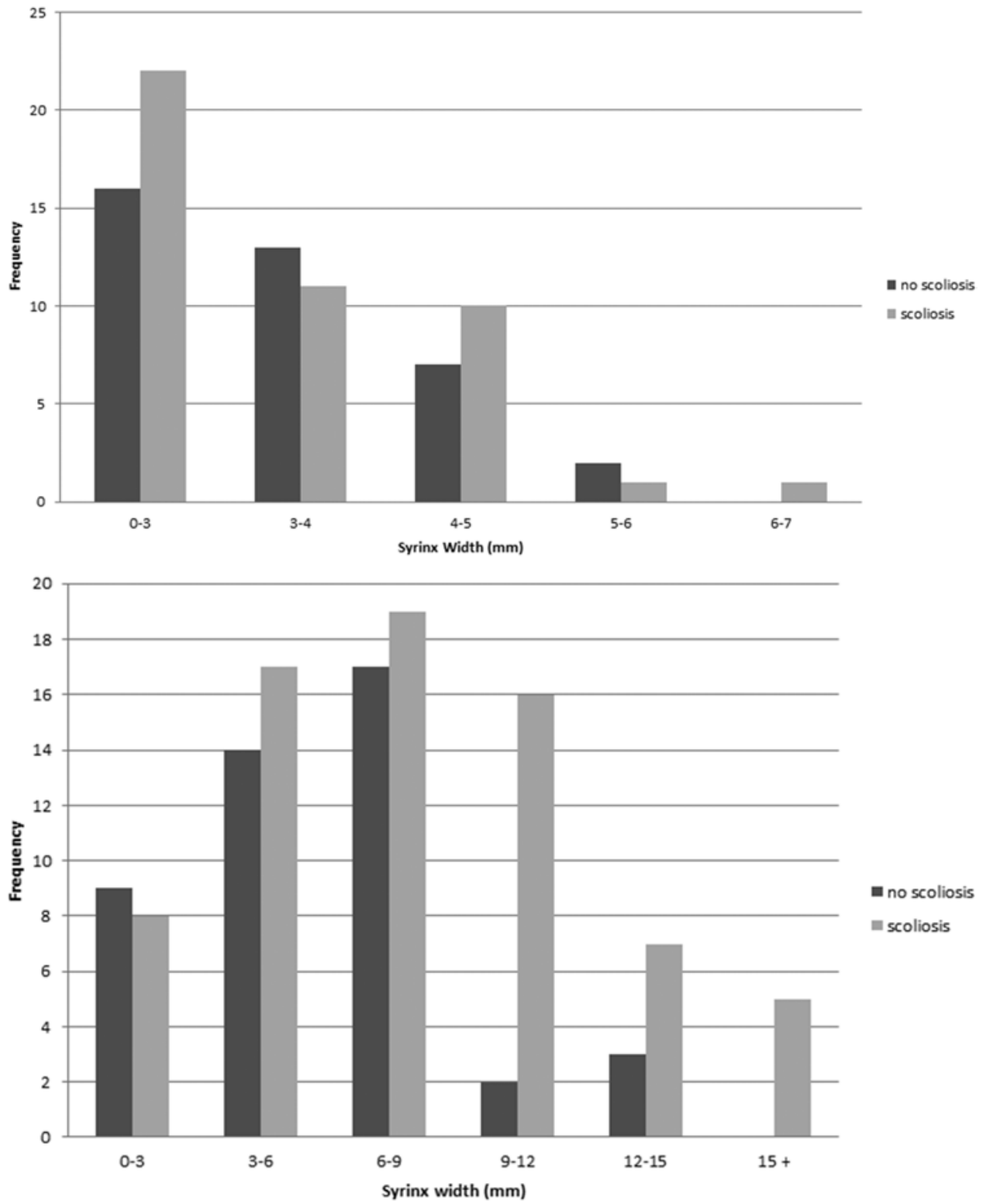

FIG. 7. Syrinx width stratified by scoliosis status for idiopathic (upper) and CM-I-associated (lower) syrinx.

is possible that their pathophysiology is different. We can speculate that idiopathic syringes may arise from stretch on the canal from the denticulate ligaments, with passive accumulation of fluid in the spinal cord.

The passive formation of thin syrinx cavities resulting from stretch could theoretically also be applied to those patients with scoliosis, whose spinal cord and ligaments may be under more tension. Scoliosis is also seen in patients with CM-I-associated syringes, which, as our data demonstrate, are typically wider. For the group of patients with syrinx as a whole, however, we found no relationship between syrinx width and the degree of scoliosis. It is possible that this lack of association reflects the fact that scoliosis is associated in some cases with wide syringes resulting from CM-I, but that in other cases scoliosis may be associated with thin syringes that form passively as a result of the curve itself. We may speculate that the wide CM-I-associated syringes may be causative for scoliosis but the thin "idiopathic" syringes may in fact form as a result of the curve itself. Since either syrinx type may be seen in patients with scoliosis, no association between syrinx width and scoliosis could be demonstrated in our group as a whole. Nevertheless, it seems likely that scoliosis remains an important cause or effect-depending on the syrinx type-of syrinx on imaging in many individuals.

In any cohort of syrinx patients, there is a need to separate those with a dilated central canal from those with thin syringes. We chose to make this distinction by considering only those patients with at least $3-\mathrm{mm}$ maximum cavity dimension on axial imaging. Prior reports on syringomyelia have included patients with cysts as small as $1 \mathrm{~mm}$ in diameter. ${ }^{14,18,23,26}$ Although our inclusion criterion for the diagnosis of syrinx rather than dilated central canal was relatively strict when compared with these prior studies, 


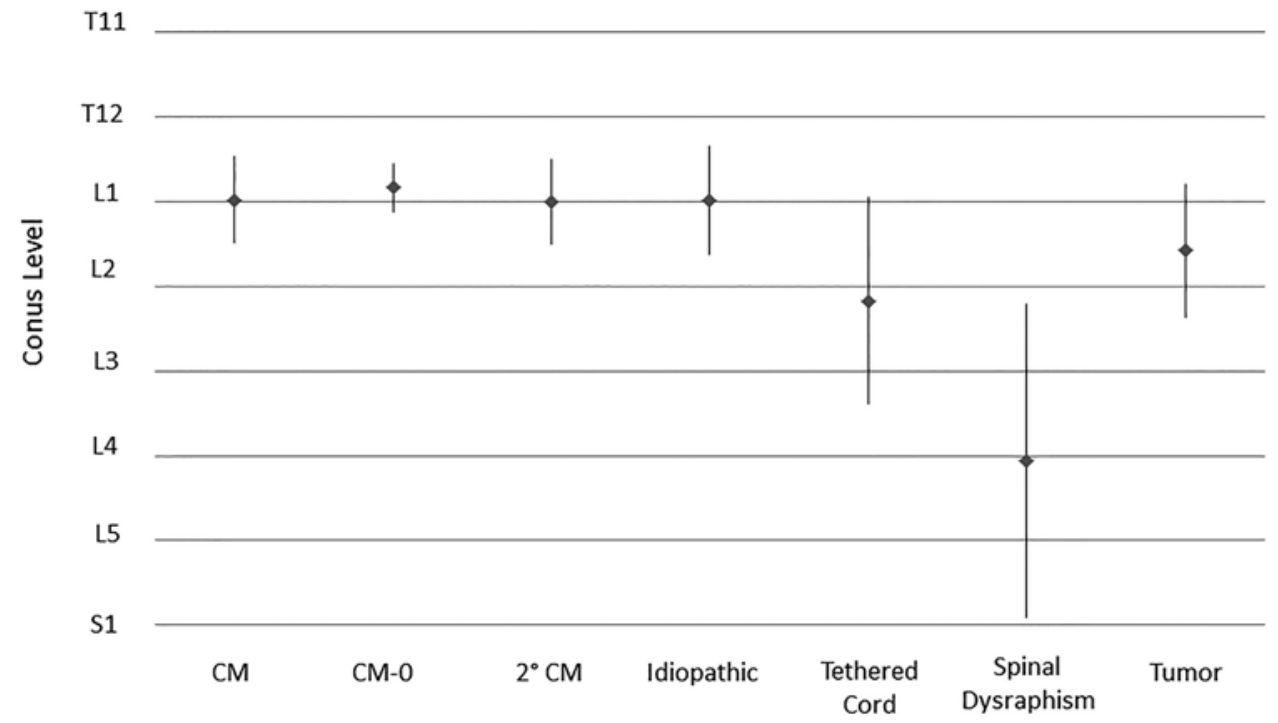

FIG. 8. Conus level for associated pathologies. Mean values are shown with error bars indicating SDs.

we acknowledge that some will undoubtedly consider patients that we have considered to have a thin syrinx to instead harbor a dilated central canal. ${ }^{12}$ Idiopathic syrinx is essentially impossible to distinguish from a dilated central canal on imaging. ${ }^{18}$ Despite this limitation, it is necessary to choose an arbitrary minimum diameter for this inclusion criterion. We chose to exclude from analysis those with a maximum axial dimension of less than $3 \mathrm{~mm}$, since smaller cavitations are rarely clinically relevant.

There are several other limitations to this retrospective analysis. All patients in this analysis were selected from a population undergoing imaging; therefore, selection bias must be considered in any interpretation of these results. We recorded conus position without respect to patient age. We do not expect this to have a meaningful impact on our conclusions since, in most individuals, the conus position is not expected to ascend to any significant extent beyond infancy. ${ }^{7,15,33,34}$ The categorization of patients with CM-0 deserves mention also, as these patients might otherwise have been grouped with the idiopathic group. We believe that $\mathrm{CM}-0$, although very rare, is a distinct entity and should be considered as a separate diagnostic category. Only 4 such patients were included in this study, and placing them within the idiopathic group would not substantially change the character of the group if these patients had been reclassified as having idiopathic syringes. Logically, however, if the syrinx morphology is strongly related to the pathophysiology of syrinx formation, then the presence of wide cervical syrinx should prompt a search for cervicomedullary CSF flow interruptions. Our methodology does not allow for any analysis of the natural history of these lesions from the data presented here. We have previously reported on the natural history of a small group of patients with CM-I and syrinx that had been selected for nonoperative management. ${ }^{29} \mathrm{We}$ excluded patients with open spinal dysraphism. Those with open dysraphism are unique in that the diagnosis is always well established by patient history. Furthermore, we believe that the treatment recommendations made for syringes in this category of patients are different due to the distinct pathophysiology of patients with open dysraphism. Finally, it must be noted that although we found associations between various conditions and syrinx size and location, this does not definitely prove causation. Prospective studies will be necessary to confirm our findings.

\section{Conclusions}

Syrinx morphology, including width and location, differs according to syrinx etiology. This suggests a distinct pathogenesis for syringes with different associated conditions. When considering CM-I and idiopathic syrinx, the combination of width greater than $5 \mathrm{~mm}$ and cranial extent in the cervical spine is highly specific for CM-I-associated syrinx. Conversely, the combination of width of $5 \mathrm{~mm}$ or less and a cranial extent in the thoracic or lumbar spine has high specificity for idiopathic syrinx. This finding may assist with assigning causation when evaluating a patient with both CM-I and syringomyelia.

\section{Acknowledgment}

The authors would like to thank Holly Wagner for providing editorial assistance.

\section{References}

1. Aitken LA, Lindan CE, Sidney S, Gupta N, Barkovich AJ, Sorel M, et al: Chiari type I malformation in a pediatric population. Pediatr Neurol 40:449-454, 2009

2. Batzdorf U, McArthur DL, Bentson JR: Surgical treatment of Chiari malformation with and without syringomyelia: experience with 177 adult patients. J Neurosurg 118:232-242, 2013

3. Bogdanov EI, Heiss JD, Mendelevich EG, Mikhaylov IM, Haass A: Clinical and neuroimaging features of "idiopathic" syringomyelia. Neurology 62:791-794, 2004

4. Chern JJ, Gordon AJ, Mortazavi MM, Tubbs RS, Oakes WJ: Pediatric Chiari malformation Type 0: a 12-year institutional experience. J Neurosurg Pediatr 8:1-5, 2011

5. Clarke EC, Stoodley MA, Bilston LE: Changes in temporal flow characteristics of CSF in Chiari malformation Type I with and without syringomyelia: implications for theory of syrinx development. J Neurosurg 118:1135-1140, 2013 
6. Cools MJ, Al-Holou WN, Stetler WR Jr, Wilson TJ, Muraszko KM, Ibrahim M, et al: Filum terminale lipomas: imaging prevalence, natural history, and conus position. J Neurosurg Pediatr 13:559-567, 2014

7. DiPietro MA: The conus medullaris: normal US findings throughout childhood. Radiology 188:149-153, 1993

8. Greitz D: Unraveling the riddle of syringomyelia. Neurosurg Rev 29:251-264, 2006

9. Hanauer DA: EMERSE: The Electronic Medical Record Search Engine. AMIA Annu Symp Proc 2006:941, 2006

10. Heiss JD, Patronas N, DeVroom HL, Shawker T, Ennis R, Kammerer W, et al: Elucidating the pathophysiology of syringomyelia. J Neurosurg 91:553-562, 1999

11. Heiss JD, Snyder K, Peterson MM, Patronas NJ, Butman JA, Smith RK, et al: Pathophysiology of primary spinal syringomyelia. J Neurosurg Spine 17:367-380, 2012

12. Holly LT, Batzdorf U: Slitlike syrinx cavities: a persistent central canal. J Neurosurg 97 (2 Suppl):161-165, 2002

13. Hwang SW, Samdani AF, Jea A, Raval A, Gaughan JP, Betz RR, et al: Outcomes of Chiari I-associated scoliosis after intervention: a meta-analysis of the pediatric literature. Childs Nerv Syst 28:1213-1219, 2012

14. Joseph RN, Batty R, Raghavan A, Sinha S, Griffiths PD, Connolly DJ: Management of isolated syringomyelia in the paediatric population-a review of imaging and follow-up in a single centre. Br J Neurosurg 27:683-686, 2013

15. Kesler H, Dias MS, Kalapos P: Termination of the normal conus medullaris in children: a whole-spine magnetic resonance imaging study. Neurosurg Focus 23(2):E7, 2007

16. Kulwin CG, Patel NB, Ackerman LL, Smith JL, Boaz JC, Fulkerson DH: Radiographic and clinical outcome of syringomyelia in patients treated for tethered cord syndrome without other significant imaging abnormalities. J Neurosurg Pediatr 11:307-312, 2013

17. Kyoshima K, Kuroyanagi T, Oya F, Kamijo Y, El-Noamany $\mathrm{H}$, Kobayashi S: Syringomyelia without hindbrain herniation: tight cisterna magna. Report of four cases and a review of the literature. J Neurosurg 96 (2 Suppl):239-249, 2002

18. Magge SN, Smyth MD, Governale LS, Goumnerova L, Madsen J, Munro B, et al: Idiopathic syrinx in the pediatric population: a combined center experience. J Neurosurg Pediatr 7:30-36, 2011

19. Nakamura M, Ishii K, Watanabe K, Tsuji T, Matsumoto M, Toyama Y, et al: Clinical significance and prognosis of idiopathic syringomyelia. J Spinal Disord Tech 22:372-375, 2009

20. Oldfield EH, Muraszko K, Shawker TH, Patronas NJ: Pathophysiology of syringomyelia associated with Chiari I malformation of the cerebellar tonsils. Implications for diagnosis and treatment. J Neurosurg 80:3-15, 1994

21. Petit-Lacour MC, Lasjaunias P, Iffenecker C, Benoudiba F, Hadj Rabia M, Hurth M, et al: Visibility of the central canal on MRI. Neuroradiology 42:756-761, 2000

22. Rocque BG, George TM, Kestle J, Iskandar BJ: Treatment practices for Chiari malformation type I with syringomyelia: results of a survey of the American Society of Pediatric Neurosurgeons. J Neurosurg Pediatr 8:430-437, 2011

23. Roy AK, Slimack NP, Ganju A: Idiopathic syringomyelia: retrospective case series, comprehensive review, and update on management. Neurosurg Focus 31(6):E15, 2011

24. Samii M, Klekamp J: Surgical results of 100 intramedullary tumors in relation to accompanying syringomyelia. Neurosurgery 35:865-873, 1994

25. Schijman E, Steinbok P: International survey on the management of Chiari I malformation and syringomyelia. Childs Nerv Syst 20:341-348, 2004

26. Singhal A, Bowen-Roberts T, Steinbok P, Cochrane D, Byrne AT, Kerr JM: Natural history of untreated syringomyelia in pediatric patients. Neurosurg Focus 31(6):E13, 2011

27. Stoodley MA, Gutschmidt B, Jones NR: Cerebrospinal fluid flow in an animal model of noncommunicating syringomyelia. Neurosurgery 44:1065-1076, 1999

28. Strahle J, Muraszko KM, Kapurch J, Bapuraj JR, Garton HJ, Maher CO: Chiari malformation Type I and syrinx in children undergoing magnetic resonance imaging. J Neurosurg Pediatr 8:205-213, 2011

29. Strahle J, Muraszko KM, Kapurch J, Bapuraj JR, Garton HJ Maher CO: Natural history of Chiari malformation Type I following decision for conservative treatment. J Neurosurg Pediatr 8:214-221, 2011

30. Tubbs RS, Beckman J, Naftel RP, Chern JJ, Wellons JC III, Rozzelle CJ, et al: Institutional experience with 500 cases of surgically treated pediatric Chiari malformation Type I. J Neurosurg Pediatr 7:248-256, 2011

31. Tubbs RS, Elton S, Grabb P, Dockery SE, Bartolucci AA, Oakes WJ: Analysis of the posterior fossa in children with the Chiari 0 malformation. Neurosurgery 48:1050-1055, 2001

32. Valentini LG, Selvaggio G, Visintini S, Erbetta A, Scaioli V, Solero CL: Tethered cord: natural history, surgical outcome and risk for Chiari malformation 1 (CM1): a review of 110 detethering. Neurol Sci 32 Suppl 3:S353-S356, 2011

33. Wilson DA, Prince JR: John Caffey award. MR imaging determination of the location of the normal conus medullaris throughout childhood. AJR Am J Roentgenol 152:1029_ 1032, 1989

34. Wolf S, Schneble F, Tröger J: The conus medullaris: time of ascendence to normal level. Pediatr Radiol 22:590-592, 1992

\section{Author Contributions}

Conception and design: Maher, Strahle. Acquisition of data: Maher, Strahle, Smith, Starr, Kapurch. Analysis and interpretation of data: Maher, Strahle, Garton. Drafting the article: Maher, Strahle. Critically revising the article: Maher, Muraszko, Garton, Strahle. Reviewed submitted version: all authors. Approved the final version: Maher. Statistical analysis: Strahle, Maher, Smith. Study supervision: Maher.

\section{Correspondence}

Cormac O. Maher, Department of Neurosurgery, University of Michigan, 1500 E. Medical Center Dr., Rm. 3552 Taubman Center, Ann Arbor, MI 48109-5338. email: cmaher@med.umich. edu. 